TITLE:

\title{
Variation in Low Intertidal Communities: Submerged vs. Emerged
}

AUTHOR(S):

HONDOLERO, DOMINIC; KONAR, BRENDA; IKEN, KATRIN; CHENELOT, HELOISE

\section{CITATION:}

HONDOLERO, DOMINIC ... [et al]. Variation in Low Intertidal Communities: Submerged vs. Emerged. Publications of the Seto Marine Biological Laboratory. Special Publication Series 2007, 8: 29-36

\section{ISSUE DATE:}

2007

URL:

http://hdl.handle.net/2433/70913

RIGHT: 


\section{Variation in Low Intertidal Communities: Submerged vs. Emerged}

DOMINIC Hondolero*, BRENDA KonAR, KATRIN IKEN and HÉLOÏSE CHENELOT

School of Fisheries and Ocean Sciences, University of Alaska Fairbanks, Fairbanks, AK 99775 USA Corresponding author's e-mail: fsdeh9@uaf.edu

Abstract Organisms living in the low rocky intertidal must cope with changing conditions of submersion and emersion on a regular basis. Some mobile organisms engage in small-scale migrations, using the tidal current for passive transport or for aid in active transport while foraging for food and escaping predation. As such, it is expected that at any given intertidal depth, mobile assemblages will vary based on whether they are submerged or emerged. This study used NaGISA (Natural Geography In Shore Areas) sampling protocols at the $1 \mathrm{~m}$ below MLLW level to examine variation in rocky intertidal mobile faunal assemblages in response to tidal immersion in Prince William Sound, Alaska. Two NaGISA survey transects were conducted at the same tidal stratum: once at high (submerged) and once at low tide (emerged). Caprellids were the only taxon to show a consistent trend of higher abundance at submersion. Amphipods, isopods and nemerteans showed different trends in abundance between sites, while crabs and errant polychaetes were more abundant during emersion. These differences could be due to water cover, species-specific movement, different species engaging in different migration patterns during the tidal cycle, patchy distribution of particular faunal species, taxon and functional group composition of the algal community, as well as the sampling technique using SCUBA at high tide versus intertidal sampling at low tide.

Key words: Intertidal, submersion, emersion, community structure, Prince William Sound, Alaska, NaGISA, variability, SCUBA

\section{Introduction}

Due to its accessibility, the intertidal zone is the marine environment that we are most familiar with in our lives and as a subject of scientific study. The change in environmental factors due to the tidal cycle is one of the most extreme of any marine environment. With a few exceptions, marine organisms are the main inhabitants of the assemblages in the intertidal zone (Coates, 1998; Bulleri et al., 2005; Davidson, 2005; Nakaoka, et al., 2006). While factors such as desiccation, overheating, freezing, and exposure to high-energy wave impacts can pose serious problems to marine organisms, the intertidal zone also is often a refuge from competitive biological interactions and predation (Connell, 1972; Bertness, 1981; Beyst, et al., 2002). The dynamic interplay of physical and biological factors in the intertidal zone is thought to be the reason for high biodiversity in rocky intertidal temperate communities that can rival or exceed subtidal communities (Suchanek, 1994). The rocky shores of the North Pacific are particularly rich in algal and faunal diversity (Paine, 1966; Zacharia and Roff, 2001; Okuda et al., 2004). In most hard-bottom intertidal regions, macroalgae add a major structural component that can serve as habitat for associated invertebrates (Hayward, 1980; Seed and O'Connor, 1981). Macroalgae offer substrate, shelter and food (Duffy and Hay, 1991; Iken, 1999) as well as protection against wave surge and desiccation (Molina-Montenegro, 2005) to associated fauna.

Migration by marine organisms into the intertidal zone during high tide has been studied on both sandy and rocky shores. On a sandy beach in Belgium, stomach content analysis of juvenile plaice caught at high tide in the surf zone found that the plaice were using the rich intertidal macrobenthic environment as a feeding ground during periods of submersion (Beyst et al., 2002). Juvenile pollock 
in rocky environments in eastern Canada also used the intertidal zone during high tide for foraging and as refuge against predators (Rangeley and Kramer, 1995). The pollock changed from their usual schooling behavior in the subtidal environment to dispersing into smaller groups or singly and hiding amongst the dense algal habitat in the intertidal zone. In Iceland, the distribution and assemblage of amphipods and isopods was found to vary at different tidal levels and different times during the tidal cycle (Ingólfsson and Agnarsson, 2003). A study carried out in the rocky intertidal zone in Ireland found a significant trend of decreasing biodiversity with increasing shore height during periods of emersion, but not submersion (Davidson et al., 2004). These studies all illustrate the significance of tidal migrations for specific taxa.

Intertidal migration, the periodic movement of species in synchrony with the tidal cycle, offers the chance to study migration and organisms' adaptations for migration on a small scale that is easier to observe than other forms of migration (Gibson, 2003). The purpose of this study was to compare the mobile faunal assemblage composition of the rocky, low intertidal environment during periods of submersion and emersion in the Northeast Pacific. Our hypothesis was that invertebrate assemblages would vary between conditions of submersion and emersion, and that mobile faunal abundances would be higher during times of submersion, since the majority of organisms found in the intertidal zone are marine organisms. Our objectives were: a) to obtain samples from the $-1 \mathrm{~m}$ tidal level during submersion and emersion that were composed of comparable substrate and algal communities and b) to compare the mobile faunal assemblages between conditions of submersion and emersion to determine if consistent trends of tidal migration could be detected.

\section{Study Sites and Methods}

The study sites chosen for this survey were Green Island and Montague Island, both located in southwestern Prince William Sound, Alaska (Fig. 1) (Green Is.: $60^{\circ} 18.131 \mathrm{~N}, 147^{\circ} 24.570 \mathrm{~W}$, Montague Is.: $\left.60^{\circ} 22.881 \mathrm{~N}, 147^{\circ} 06.589 \mathrm{~W}\right)$. Both sites are located on the northern shores of their

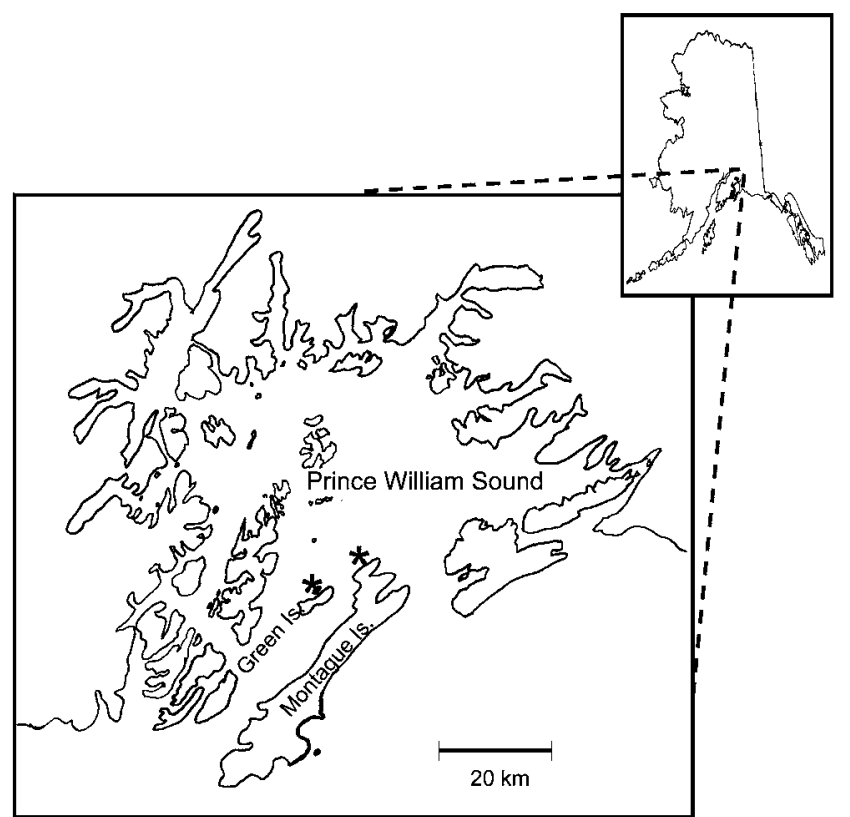

Fig. 1. Map of study area in Prince William Sound, Alaska. Study sites Montague Island (MI) and Green Island (GI) are marked with asterisks. 
respective islands and both sites are semi-exposed to waters entering Prince William Sound with the Alaska Coastal Current. The substrate at Green Is. is mainly composed of large boulders, while Montague Is. has more bedrock visible and the slope of the shore is slightly steeper.

The Natural Geography In Shore Areas (NaGISA) protocol was used in June 2004 to sample assemblage composition (Nakashizuka and Stork, 2002; see Rigby et al., 2007 for fuller description). For this study, these protocols sampled the assemblage at the $-1 \mathrm{~m}$ subtidal depth where whole assemblage collections were completed in five replicate $25 \times 25 \mathrm{~cm}$ quadrats along a $30 \mathrm{~m}$ transect. First, a subtidal survey (submersion) of the $-1 \mathrm{~m}$ level was conducted at each site shortly after the peak of high tide. For this survey, the $25 \times 25 \mathrm{~cm}$ quadrats were placed randomly along the transect, and the assemblage was scraped and collected into $63 \mu \mathrm{m}$ mesh bags. Digital photos and field notes from the algal assemblage composition of quadrats from these subtidal surveys were then used to find and sample similar quadrats along the $-1 \mathrm{~m}$ intertidal transect during the following minus tide (emersion). In the lab, collections from submersion and emersion quadrats were sorted into macroalgae and invertebrates. Algae were identified to the lowest taxonomic level possible, individual kelp stipes counted, and the damp weight of each algal taxon was measured. Invertebrates from all quadrats were also identified to the lowest taxonomic level possible, individuals of each taxon were counted, and damp weight was determined. Multi-dimensional scaling (MDS) (PRIMER v.6) of log-transformed biomass (algae) and abundance (invertebrates) data was used to compare algal assemblage composition and invertebrate assemblage composition at each site. DATA were log-transformed to meet assumptions of normality and equal variances. A two-tailed t-test on log-transformed invertebrate abundance date was used to evaluate significant differences in invertebrate taxon abundance under emerged and submerged conditions by site.

\section{Results}

With respect to algal assemblages, the MDS ordination shows a reasonably close pairing of subtidal and intertidal quadrats (Fig. 2). This ordination also shows some overlap of algal assemblages between sites. In contrast, MDS ordination of invertebrate assemblages shows a general separation of

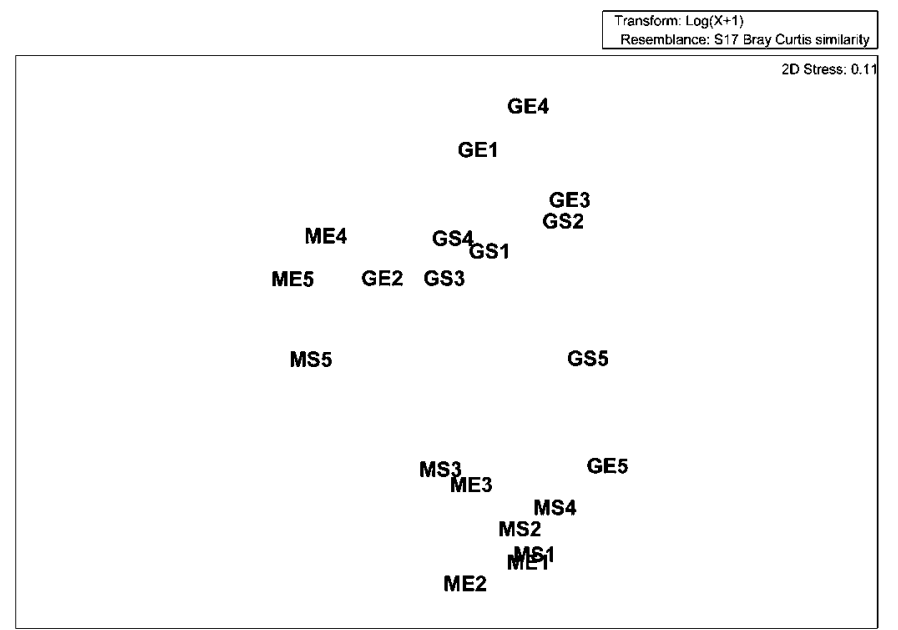

Fig. 2. MDS plot representing algal composition and biomass by genus for each quadrat (plot based on $(\log +1)$ transformed biomass data). Quadrats denoted with 'E' are emerged, those with 'S' are submerged. 


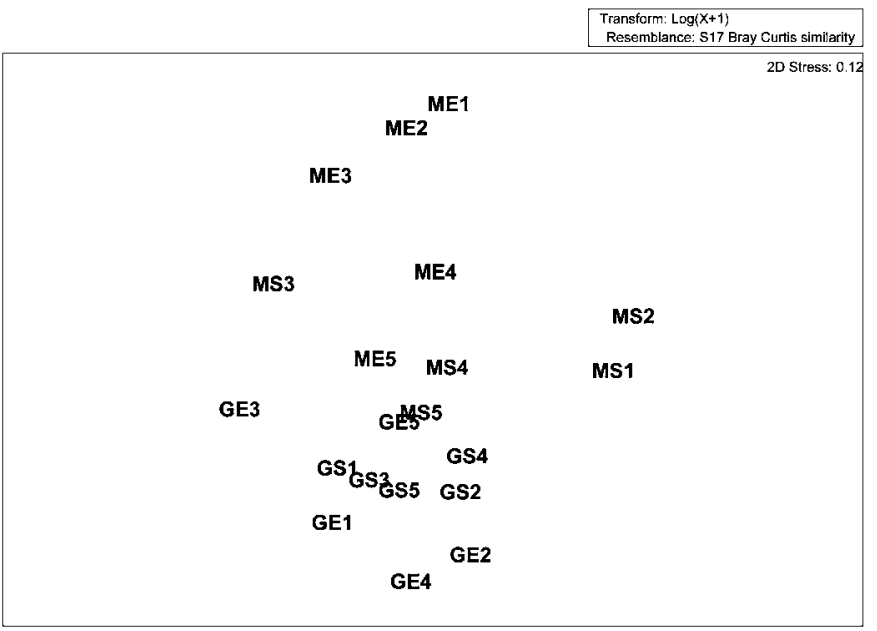

Fig. 3. MDS plot representing invertebrate composition and abundance by taxa for each quadrat (plot based on $(\log +1)$ transformed abundance data). Quadrats denoted with 'E' are emerged, those with 'S' are submerged.

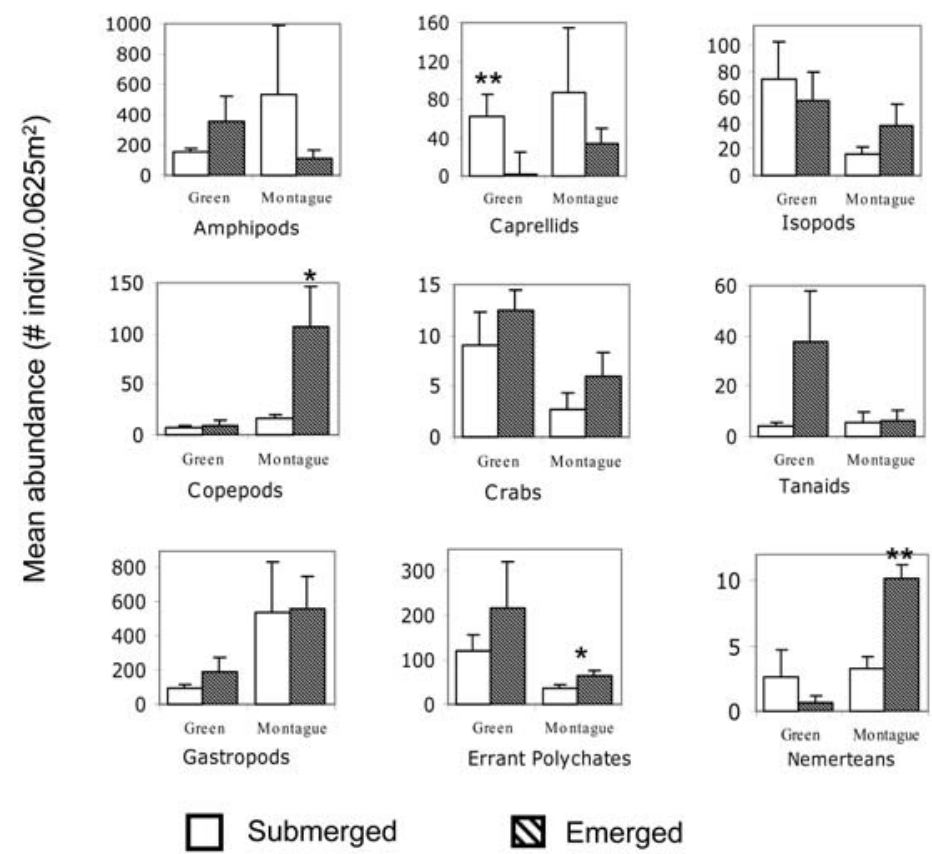

Fig. 4. Abundance of invertebrate taxa under emerged and submerged conditions at both study sites. Significant differences (2-tailed t-test) are denoted with asterisks ${ }^{*} p<0.05,{ }^{* *} p<0.01$. 
the two sites and a relatively tighter grouping of the Green Is. quadrats (Fig. 3). Amphipods, polychaetes and gastropods were consistently among the most numerous invertebrate taxa found, independent of site or submersion condition. Chitons and echinoderms occurred at both sites and under both conditions but at very low numbers and were hence excluded from the analysis. Mean abundances ( \pm 1 S.E.) of mobile invertebrate taxa showed different distribution patterns between taxa and sites under conditions of submersion/emersion (Fig. 4.). Caprellid amphipods were the only group that had higher abundances at submerged conditions at both sites, although these differences were only significant at Green Is. (2-tailed t-test, $p=0.0004$ ). Nemertean and isopod abundance in emerged and submerged conditions differed between islands, with both taxa having higher abundances during submersion at Green Is. but lower abundances while submerged at Montague Island. Of these, only the higher abundance of nemerteans during emersion at Montague Is. was statistically significant $(p=0.007)$. All other taxa had slightly higher or equal abundances at emerged conditions at both sites. Beside the abovementioned nemerteans, the higher abundances under emerged conditions were statistically significant only for copepods $(p=0.04)$ and errant polychaetes $(p=0.05)$ at Montague Island and for tanaids at Green Is. $(p=0.05)$.

\section{Discussion}

Although some significant differences in mobile invertebrate abundances were detected under submerged and emerged conditions, our hypothesis that invertebrates should be more abundant at submerged conditions was not supported since no overall pattern in mobile assemblage composition was seen as a result of different water cover. Some of the differences found between taxa may be due to species-specific variations in migration patterns in response to submersion and emersion. Tidal migration patterns can vary between closely related species and also within the same species at differing points during ontogeny (Gibson, 2003). While differences in distribution patterns can be expected for various invertebrate taxa based on their different ecological requirements, consistent trends between the two islands for any one invertebrate group would indicate that the observed pattern is ecologically meaningful. For example, the higher abundance of caprellid amphipods in submerged conditions at both sites may indicate that caprellids in fact exhibit some tidal migration with the incoming tide. A similar trend was not found for other amphipods. This is not surprising, as it has been shown that even different species within the same genus of intertidal amphipods and isopods exhibit different tidal migration patterns (Ingolfsson and Agnarsson, 2003). Higher abundances of crabs and polychaetes at emerged conditions may indicate that these taxa seek shelter closer to the rocks and between algae during times of emersion, likely to avoid desiccation or predation by predators such as shorebirds. Predation of limpets by birds during times of emersion can affect the composition of intertidal faunal assemblages (Wootton, 1993). Cryptic migration, the use of cryptic habitats such as the undersides of rocks, cracks or holes in the substrate or algae, was thought to be the type of migration used by most fauna in a study of the rocky intertidal in Ireland (Bell and Turner, 2003).

Besides submersion and emersion, differences detected in assemblage composition could also have resulted from several other factors. While the MDS of algal biomass shows corresponding quadrats within a site sampled at low and at high tide overall to be reasonably similar (Fig. 2), this was not the case for all quadrats. Paired quadrats that were sampled during the second survey were selected based on the presence and dominance of algal genera found during the first survey, but actual biomass may have been different between paired quadrats. The different algal assemblages found at each site and within paired quadrats within a site also could have affected the faunal composition and distribution patterns. Algal-associated epifauna can be specific to algal species as well as algal functional forms (Lippert et al., 2001). On Australia's Great Barrier Reef, the crab Caphyra rotundifrons selectively used patches of the chemically defended green alga Chlorodesmis fastigiata as 
a refuge from predators (Hay et al., 1989). Faunal assemblages associated with the kelp Laminaria hyperborea along the Norwegian coast were associated as different assemblages with different parts of the kelp thallus and the epiphytic algae growing on the stipe (Christie et al., 2003). Hence, variation in the relative amounts of different algal genera or functional forms may explain some of the differences in quadrat algal similarity as well as differences in associated faunal similarity. These faunal differences may be amplified during the emersion/submersion transition as different invertebrate taxa may tidally migrate differently depending on the quantitative availability of substrate (i.e., algae).

Inherent assemblage patchiness may be contributing to some of the differences seen in invertebrate abundance between low and high tide conditions. Patchiness can be a result of smallscale variations, selective biological pressure such as predation, or variation in environmental factors. In an experiment conducted in the rocky, shallow subtidal in Torch Bay, Alaska, sea star predation on herbivores was shown to create mosaic patterns of algal communities (Duggins, 1983). As a result of the herbivore free patches that Pycnopodia helianthoides left behind and the rapid successional dynamics of the subtidal algal community, significant differences in algal communities were found along the same subtidal level. As another mechanism influencing patchiness, flow rate within an intertidal estuary in Maine was shown to affect both invertebrate species density and the relative strength of top-down and bottom-up processes between sites (Leonard et al., 1998). Flow rate and exposure was also deemed critical in intertidal regions in Ireland (Davidson, 2005). Possibly, patchiness and differences in flow rate and exposure between our sites may have affected the mobile invertebrate assemblage structure over the tidal cycle.

The differences detected in faunal assemblages in our study also could be caused by the differences in methods used during submerged (SCUBA) and emerged (intertidal scraping) surveys. Some methodological biases may be introduced by SCUBA techniques that may result in under representation of less common organisms (Leonard and Clark 1993, Dethier et al., 1993). To minimize the escape of the more mobile fauna during collection of submerged samples the mesh bags were placed as close as possible to the substrate being scraped. However, due to environmenta conditions during underwater sampling (current and wave action) as well as escape responses, the abundance of inconspicuous, highly mobile invertebrates such as copepods, amphipods, and isopods may have been underestimated during submersion. The authors were not able to quantify this difference, if any, as a result of this study.

It seems that a variety of factors are contributing to the distribution of assemblages in rocky intertidal zones of the northern Pacific. Elucidating regional and global diversity patterns has long been a goal in marine sciences to better understand the drivers of assemblage structure and, hence, vulnerability and resilience of assemblages to various stressors (Witman, 2004). Efforts such as NaGISA have developed standardized protocols that will facilitate comparisons on multiple spatial and temporal scales. This study emphasized that certain environmental conditions may impact assemblage composition and that careful monitoring of environmental factors during sampling is necessary, as is requested as part of the standardized NaGISA protocols. This study has shown that abundance of certain taxa within assemblages along the lower intertidal strata can differ depending on whether they are emerged or submerged. This should be considered in the interpretation of local and regional biodiversity patterns. We suggest, however, that differences observed here in invertebrate taxa patterns between submerged and emerged conditions were not large or consistent enough between sites to influence comparisons on larger spatial scales, such as global comparisons.

\section{Acknowledgements}

We would like to thank the International NaGISA group, the Census of Marine Life, and the Sloan Foundation for their commitment to increasing global awareness of marine biodiversity. We particularly thank 
Robin Rigby, Gayle Hansen, and Jeremy Bahr for their help in the field. We appreciate the logistical support we received from Neal Oppen. This project was funded by the Gulf Ecosystem Monitoring Program (Konar and Iken) and EPSCoR (Hondolero).

\section{References}

Bell, J.J. and Turner, J.R. 2003. Temporal and spatial variability of mobile fauna on a submarine cliff and boulder scree complex: a community in flux. Hydrobiologia, 503, 171-182.

Bertness, M. D. 1981. Predation, physical stress, and the organization of a tropical rocky intertidal hermit crab community. Ecology 62 (2), 411-425.

Beyst, B., Vanaverbeke, J., Vincx, M., Mees, J. 2002. Tidal and diurnal periodicity in macrocrustaceans and demersal fish of an exposed sandy beach, with special emphasis on juvenile plaice Pleuronectes platessa. Marine Ecology Progress Series, 225, 263-274.

Bulleri, F. Chapman, M.G., Underwood, A.J. Intertidal assemblages on seawalls and vertical rocky shores in Sydney Harbour, Australia. Austral Ecology, 30, 655-667.

Christie, H., Jorgensen, N.M., Norderhaug K.M., Waage-Nielson E. 2003. Species distribution and habitat exploitation of fauna associated with kelp (Laminaria hyperborea) along the Norwegian coast. Journal of the Marine Biological Association of the United Kingdom, 83, 687-699.

Coates, M. 1998. A comparison of intertidal assemblages on exposed and sheltered tropical and temperate rocky shores. Global Ecology and Biogeography Letters, 7, 115-124.

Connell, J.H. 1972. Community interteractions on marine rocky intertidal shores.

Annual Review of Ecology and Systematics, 3, 169-192.

Davidson, I.C. 2005. Structural gradients in an intertidal hard-bottom community: examining vertical, horizontal, and taxonomic clines in zoobenthic biodiversity. Marine Biology, 146, 827-839.

Davidson, I.C., Crook, A.C., Barnes, D.K.A. 2004. Macrobenthic migration and its influence on the intertidal diversity dynamics of a meso-tidal system. Marine Biology, 145, 833-842.

Dethier, M.N., Graham, E.S., Cohen, S., Tear, L.M. 1993. Visual versus random-point percent cover estimations: 'objective' is not always better. Marine Ecology Progress Series, 96, 93-100.

Duffy, J.E., Hay, M.E. 1991. Food and shelter as determinants of food choice by an herbivorous marine amphipod. Ecology, 72, 1286-1298

Duggins, D.O. 1983. Starfish predation and the creation of mosaic patterns in a kelp-dominated community. Ecology 64 (6), 1610-1619.

Gibson, R.N. 2003. Go with the flow: tidal migration in marine animals. Hydrobiologia, 503, 153-161.

Hay, M.E., Pawlik, J.R., Duffy, J.E., Fenical, W. 1989. Seaweed-herbivore-predator interactions: host-plant specialization reduces predation on small herbivores. Oecologia, 81, 418-427.

Hayward, P.J. 1980. Invertebrate epiphytes of coastal marine algae. In, Price JH, Irvine DEG, Farnham WF (eds.) The shore environment, ecosystems. Academic Press, London, pp. 761-787.

Iken, K. 1999. Feeding ecology of the Antarctic herbivorous gastropod Laevilacunaria antarctica Mertens. Journal of Experimental Marine Biology and Ecology, 236, 133-148.

Ingólfsson, A. and Agnarsson, I. 2003. Amphipods and isopods in the rocky intertidal: dispersal and movements during high tide. Marine Biology, 143, 859-866.

Leonard, G.H. and Clark, R.P. 1993. Point quadrat versus video transect estimates of the cover of benthic red algae. Marine Ecology Progress Series, 101, 203-208.

Leonard, G.H., Levine, J.M., Schmidt, P.R., Bertness, M.D. 1998. Flow-driven variation in intertidal community structure in a Maine estuary. Ecology, 79 (4), 1395-1411.

Lippert, H, Iken, K, Rachor, E, Wiencke, C. 2001. Macrofauna associated with macroalgae in the kongsfjord (Spitzbergen). Polar Biology, 24, 512-522.

Molina-Montenegro, M.A., Muñoz, A., Badano, E.I., Morales, B.W., Fuentes, K.M., Cavieres, L.A. 2005. Positive associations between macroalgal species in a rocky intertidal zone and their effects on the physiological performance of Ulva lactuca. Marine Ecology Progress Series, 292, 173-180.

Nakaoka, M., Ito N., Yamamoto, T., Okuda, T., Noda, T. 2006. Similarity of rocky intertidal assemblages along the Pacific coast of Japan: effects of spatial scales and geographic distance. Ecological Research, 21: 425-435. Nakashizuka, T. and Stork, N. 2002. Biodiversity Research Methods: IBOY in Western Pacific and Asia. Kyoto 
University Press, Japan. 216 pp.

Okuda, T., Noda, T., Yamamoto, T., Ito, N., Nakaoka, M. 2004. Latitudinal gradient of species diversity: multiscale variability in rocky intertidal sessile assemblages along the Northwestern Pacific coast. Population Ecology, 46, 159-170.

Paine, R.T. 1966. Food web complexity and species diversity. The American Naturalist, 100, 65-75.

Rangeley, R.W. and Kramer, D.L. 1995. Tidal effects on habitat selection and aggregation by juvenile Pollock Pollachius virens in the rocky intertidal zone. Marine Ecology Progress Series, 126, 19-29.

Rigby, P.R., Kato, T., Riosmena-Rodriguez, R. 2007. NaGISA Rocky Shore Protocol. In, Rigby, P.R., Iken, K. and Shirayama, Y. (eds) Sampling Biodiversity in Coastal Communities: NaGISA Protocols for Seagrass and Macoalgal Habitats. Kyoto University Press, Japan. pp. 17-21.

Seed, R. and O'Connor, R.J. 1981. Community organization in marine algal epifaunas. Annual Review in Ecology and Systematic, 12, 49-74.

Suchanek, T.H. 1994. Temperate Coastal Marine Communities: Biodiversity and Threats. American Zoologist, 34 (1), 100-114.

Witman, J.D., Etter R.J., Smith F. 2004. The relationship between regional and local species diversity in marine benthic communities: A global perspective. Proceedings of the National Academy of Sciences, 101, 1566415669.

Wootton, J.T. 1993. Indirect effects and habitat use in an intertidal community: interaction chains and interaction modifications. The American Naturalist, 141, 71-89.

Zacharias, M.A., Roff, J.C. 2001. Explanations of patterns of intertidal diversity at regional scales. Journal of Biogeography, 28, 471-483. 